\title{
A Comparison of the Conventional and Reverse Houldcroft Type Hot Cracking Tests in A5052 Aluminum Alloy Sheet*
}

\author{
By Mitsuaki KATOH**, Kazumasa NISHIO** and Shizuo MUKAE**
}

\begin{abstract}
The influence of the heat input on the crack ratio (length of crack versus welded length) has been investigated using both the conventional and reverse Houldcroft type hot cracking tests for A5052 aluminum alloy sheet. In the conventional type test, where the temperature distribution around the molten pool is the main factor, the crack ratio decreased linearly when the heat input increased. In the reverse type test, where restraint is the main factor instead of the temperature distribution, the crack ratio increased when the heat input increased. This is the same tendency which is experienced actually in welding. Hence, the reverse type test is recommended as a better test. The study also showed that the crack would propagate more easily in the case of equiaxed dendrites than in the case of columnar crystals.

The rotation angle at the tip of the crack was observed using a video camera from the back side of the specimen. The rotation angle had a maximum value of about 0.08 rad near the start of the welding, and decreased gradually as the crack propagated. The crack stopped when the rotation angle reached from about 0.01 to 0.03 rad. It was made clear that the rotation angle greatly influences the propagation and arrest of the crack.
\end{abstract}

Key Words: Houldcroft type hot cracking test, A5052 aluminum alloy, rotation angle, heat input, restraint, temperature distribution; crack ratio, reverse Houldcroft type hot cracking test

\section{Introduction}

The Houldcroft type hot cracking test (hereafter termed the conventional type test) has been widely used as a test method of weld solidification cracking of aluminum alloys ${ }^{11}$. In this method, the length of slots, which are machined on both sides of a specimen, increases linearly in the direction from weld-start edge to weld-end edge. Crack susceptibility of welding is evaluated by the length of the crack, which is initiated at the weld-start. A simple model of force necessary to close the crack is given, based on the thermal strain which opens the $\mathrm{crack}^{2)}$. Another report says that the crack is developed in aluminum alloys when the brittle region near the end of the crater deforms more than a certain amount due to the rotational deformation during welding ${ }^{3)}$. In the case of the conventional type test, the crack susceptibility decreases when the weld heat input increases ${ }^{2)}$, whereas in actual welding usually the crack susceptibility increases when the heat input increases. Because of this disagreement with actual experience, Ando et al. proposed a reverse
Houldcroft type test ${ }^{3)}$. They did not, however, make clear the effect of the heat input.

The cracks in the conventional type test were continuous and the momentary halting of cracks appeared to be associated with the presence of the slots ${ }^{4}$. For a crack to be halted in a slotted specimen the weld pool has to reach a region where the slots are so deep that the strain field generated around the weld is affected such as to reduce the strain behind the pool and encourage the crack to halt. The temperature distribution will also be altered by the presence of the slots and this in turn, alters the strain pattern ${ }^{5)}$.

There are few papers in which the local deformation, as measured by the rotation angle, was determined during weldidng to clarify the effect of the heat input. This rotation angle is a measure of the rotational deformation around the weld due to thermal strain which causes cracking. An increase in the rotation angle is caused by a larger rotational deformation and thus an increase likelihood of crack propagation. Obviously, if cracking does not occur, no rotation angle can be measured. In the present investiga-

* Received: 7 September 1993.

** Member, Kyusyu Institute of Technology, 1-1, Sensuicho, Tobataku, Kitakyusyu City 
tion the effects of the heat input and the solidification structures on the crack ratio, using both the conventional type and the reverse type Houldcroft tests, were determined for A5052 aluminum alloy. The rotation angles were measured using a video camera during welding to investigate the difference between the tests.

\section{A Material Used and Experimental Proce- dures}

The material used in this investigation is A5052 aluminum alloy of $2 \mathrm{~mm}$ thickness, whose chemical compositions are $\mathrm{Cu}: 0.04, \mathrm{Si}: 0.10, \mathrm{Fe}: 0.28$, $\mathrm{Mn}: 0.16, \mathrm{Mg}: 2.40, \mathrm{Zn}: 0.01, \mathrm{Cr}: 0.19, \mathrm{Ti}: 0.02$ and $\mathrm{Al}: \mathrm{Bal}$. (mass\%). The shape of the specimen in the case of the conventional type is as shown in Fig. 1, with the welding performed from left to right. The shape of the specimen in the case of the reverse type will be shown later.

Bead-on-plate welding was performed along the center line of the specimen in the longitudinal direction using GTA (electrode positive). Several welding speeds were used between 2.5 and $12.5 \mathrm{~mm} / \mathrm{s}$ and for each speed several welding currents were employed.

Rotation angles, which are the measure of the rotational deformation, were observed from the back side of the specimens using a video camera. A method for measuring the rotation angle $\theta$ is represented schematically in Fig. 2. Scribed lines, which were straight before welding, deviate as shown in Fig. 2 when a weld crack is propagating.

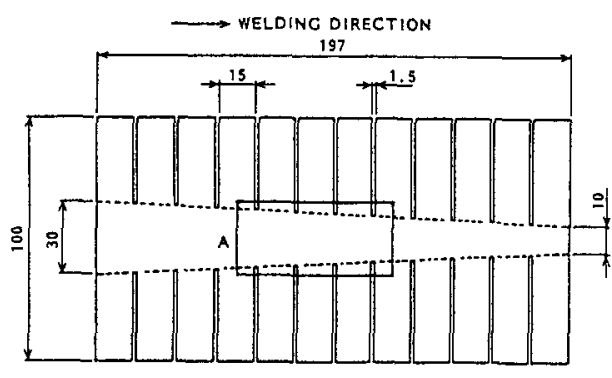

DETAIL A

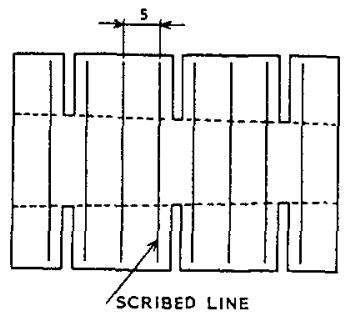

Fig. 1 Shape and dimensions of a specimen of the conventional Houldcroft type hot cracking test.
This phenomenon shows that rotational deformation occurs during welding. The rotation angle, defined as shown in Fig. 2, was measured on a television monitor.

\section{Conventional Type Test Results}

\subsection{Influence of welding conditions}

Fig. 3 shows the measured relation between the crack ratio and the welding speed v. The crack ratio is defined as the ratio of the length of the crack to the welding length $(150 \mathrm{~mm})$. The welding currents were controlled so as to obtain the bead width of about $10 \mathrm{~mm}$ at each welding speed. When the welding speed increased, the crack ratio increased approximately linearly. When the welding speed was faster than $7.5 \mathrm{~mm} /$ $s$ the crack ratio levelled off. The solidification structures observed in the center of the weld metal, where the crack was propagating, were columnar crystals (stray crystals ${ }^{6)}$ ). When the welding speed was less than $5.0 \mathrm{~mm} / \mathrm{s}$ and equiaxed dendrites in the case of the welding speed more than $6.7 \mathrm{~mm} / \mathrm{s}$. In the case of columnar crystals individual short cracks were observed, but in the case of equiaxed dendrites only one main crack propagated continuously as shown schematically in Fig. 4. Accordingly, it appears that the crack

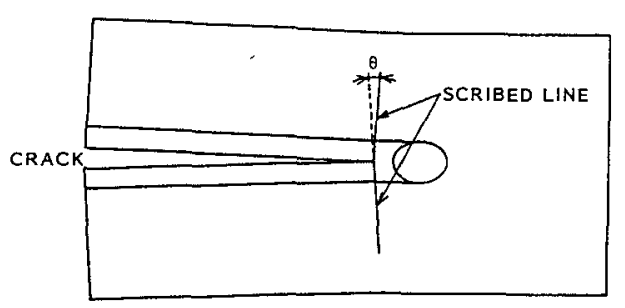

Fig. 2 Schematic representation of the definition of the rotation angle $\theta$.

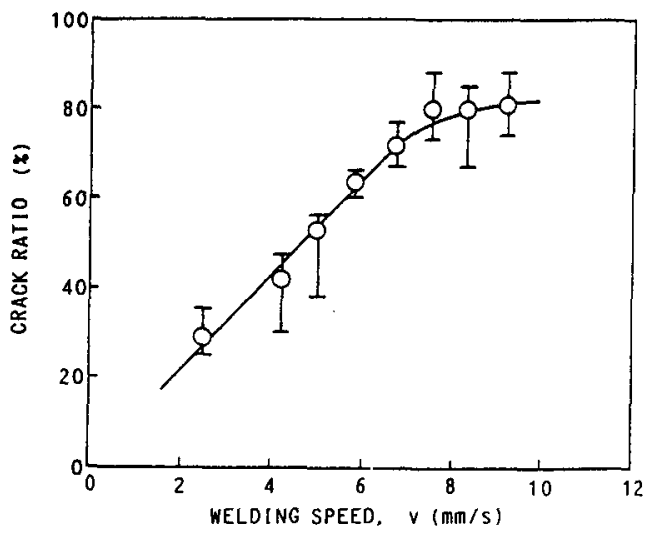

Fig. 3 Relation between crack ratio and welding speed for the conventional type test. 


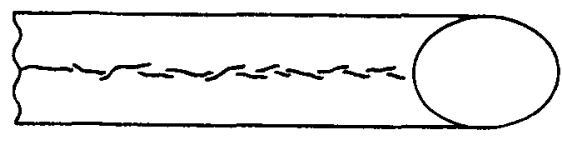

(a) Low welding speed

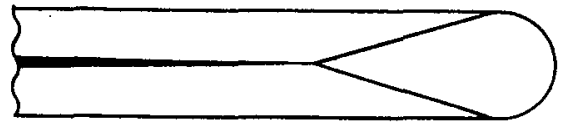

(b) High welding speed

Fig. 4 Relation between welding speed and feature of crack propagation.

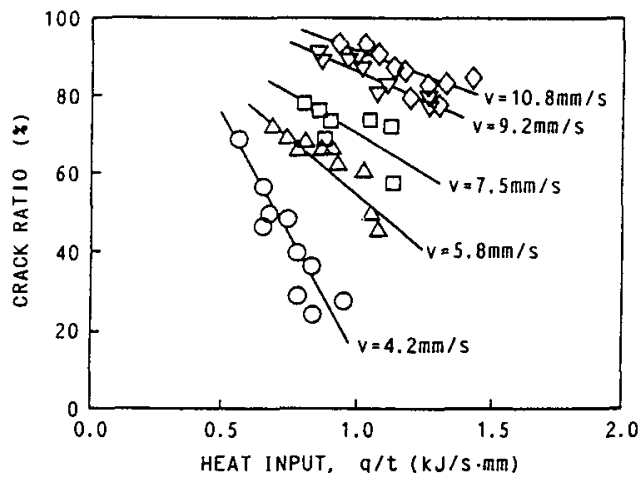

Fig. 5 Relation between crack ratio and heat input $q / t$ for the conventional type test.

propagate more easily in the case of equiaxed dendrites than with columnar crystals. F. Matsuda et al. reported that grain refinement of weld metal reduces bead-crack susceptibility, though it is not a sufficient condition ${ }^{7}$.

Fig. 5 shows the relation between the crack ratio and heat input $q / t(q=I \cdot E, I$ : welding current (A), E : arc voltage (V), $t$ : thickness of a specimen $(\mathrm{mm}))$. The crack ratio decreased linearly as $\mathrm{q} / \mathrm{t}$ increased for each welding speed. The slope of the crack ratio versus heat input decreases as the welding speed was increased. Ando et al. reported that the rotational deformation would occur because of the temperature distribution due to welding, i.e., the differential expansion caused by the temperature gradient around the weld ${ }^{8}$. Therefore, it would be expected that the rotational deformation would decrease due to an increase of weld heat input (i.e., welding current) at a given welding speed, decreasing the crack ratio as observed. The rotational deformation during the crack propagation will be discussed later.

In the conventional type test, two opposing effects occur when the heat input increases. First, the temperature distribution tends to be more uniform, which reduces the rotational deformation. The reflection of the heat might occur in

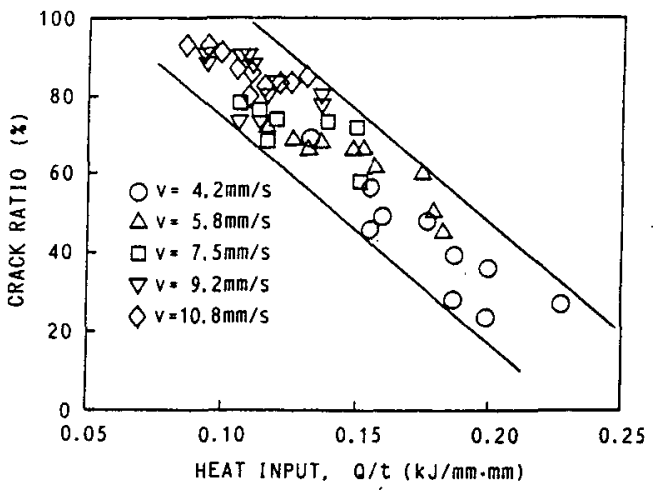

Fig. 6 Relation between crack ratio and heat input $Q / t$ for the conventional type test.

this case ${ }^{3)}$, because the width of the specimen is $100 \mathrm{~mm}$ as shown in Fig. 1. This would promote the temperature distribution to be more uniform. On the other hand, the restraint becomes smaller due to the increase of both the depths of the slots and plastic zone around the weld, which increases the rotational deformation and thus promotes cracking.

It should be noted that the influence of restraint in the Houldcroft test is opposite to the usual expectation that increased restraint increases cracking. In the Houldcroft type test the crack continues to propagate if the rotational deformation during welding is sufficient to open up the propagating crack behind the pool. In actual welding situations, restraint holds the parts to be joined in place, reducing rotational deformation but causing plastic compression of the hot heat affected zone. Subsequent cooling results in a tensile strain whose magnitude increases with increased restraint on heating, thus developing cracking.

The observation that the Houldcroft crack stops shows that the effect of the reduced temperature distribution is superior to the decrease of the restraint in the conventional type test. The fact that the crack ratio increases when welding speed increases, at the same heat input, is due to the temperature distribution becoming steeper with higher welding speeds.

Fig. 6 shows the relation between the crack ratio and heat input $Q / \mathrm{t}(\mathrm{Q}=\mathrm{I} \cdot \mathrm{E} / \mathrm{v}, \mathrm{v}$ in $\mathrm{mm} / \mathrm{s})$. This measure of heat input combines the usual heat input per unit distance with the specimen thickness (which in fact was constant). As is seen in Fig. 6 the crack ratio decreased linearly as $\mathrm{Q} / \mathrm{t}$ increased, independent of the welding speed, though there was some scatter in the data. This is consistent with the above interpretation. 


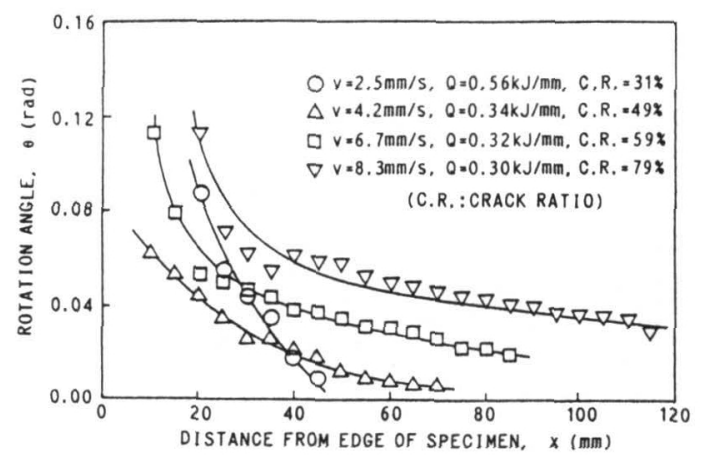

Fig. 7 Change of rotation angle in the process of crack propagation for the conventional type test.

\subsection{Study of rotation angle}

Fig. 7 shows the change of the rotation angle during the process of crack propagation as a function of $\mathrm{x}$, the distance from the starting edge of the specimen. C.R. in Fig. 7 is the crack ratio observed. The rotation angle was measured at the tip of the crack in each location during the process of crack propagation. In the case of $\mathrm{v}=$ $2.5 \mathrm{~mm} / \mathrm{s}$, rotation angle decreased abruptly as the distance increased and the crack ratio was $31 \%$. In the case of $\mathrm{v}=4.2 \mathrm{~mm} / \mathrm{s}$, the rotation angle near the start of the welding had a smaller value of $0.06 \mathrm{rad}$ and the rotation angle decreased gradually as the distance increased. In the case of the welding speed larger than $5.0 \mathrm{~mm} / \mathrm{s}$, the rotation angle decreased abruptly near the start of the welding and thereafter decreased approximately linearly as the distance increased. The values of the rotation angle at the positions where the cracks stopped were from about 0.01 to $0.03 \mathrm{rad}$, though some differences were obtained when the welding conditions were changed. As mentioned above, the rotation angle decreased as the distance increased. Hence, it may be concluded that the degree of the rotational deformation affects strongly the propagation and arrest of the crack. According to the previous authors the reason why the crack stops in the conventional type test would be the relaxation of restraint ${ }^{1)}$ and the uniformity of the temperature distribution ${ }^{3}$. Both of these factors are reflected in the rotational deformation, which then can be viewed as a main factor for the propagation of the crack as shown in Fig. 7. With high restraint, the rotational deformation is limited and the crack cannot propagate as will be discussed further later. Hence, it is proposed that with the conventional type test the crack will stop due to the uniformity of the temperature distribution.

This can be explained more fully as follows.

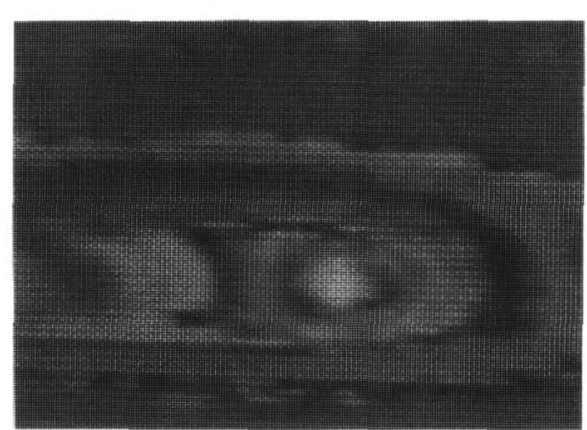

(a)

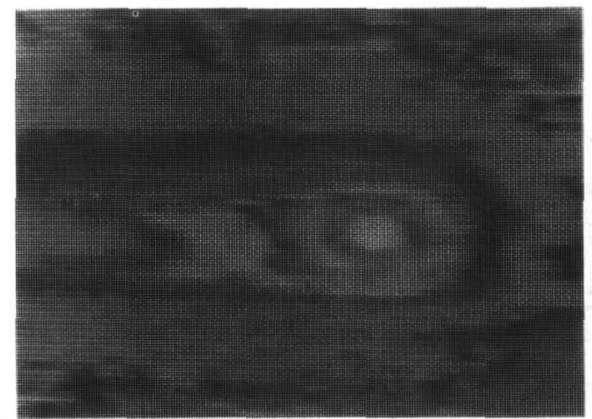

(b)

Fig. 8 Examples of temperature distributions $(\mathrm{v}=4.2 \mathrm{~mm} / \mathrm{s}, \quad \mathrm{I}=55 \mathrm{~A}, \mathrm{E}=20 \mathrm{~V})$. With slots, (b) Without slots.

Fig. 8(a) and (b) show examples of the temperature distributions around the molten pool as measured by an infrared camera on the back side of the specimens. Fig. 8(a) is the result with slots as shown in Fig. 1, and Fig. 8(b) is the result without slots for a given set of welding conditions. The infrared camera represents the temperature by color tones. Each color tone observed here has the temperature range of $16^{\circ} \mathrm{C}$. The small elliptical part near the center of each figure corresponds to the position beneath the arc. The temperatures here were 700 and $696^{\circ} \mathrm{C}$ in cases of Fig. 8(a) and (b), respectively. The temperature, of course, decreased with distance away from the arc. As is apparent by comparing Fig. 8(a) with (b), the temperature decreased less quickly in the longitudinal direction with slots (Fig. 8(a)) than without slots (Fig. 8(b)). That is, the temperature distribution tends to be more uniform in the case of the specimen with slots. So, the rotation angle decreases when the distance increases as shown in Fig. 7 and eventually the crack stops.

\section{Reverse Type Test Results}

\subsection{Shape and dimensions of reverse type speci- men}

Fig. 9 shows the relation between the crack ratio and the width of specimen w. Some welds 
were made using plain rectangular sheets $250 \mathrm{~mm}$ long, and different sheet width, for a range of welding conditions. The welding length was 200 $\mathrm{mm}$ in this case. In cases of $\mathrm{v}=4.2$ and $5.8 \mathrm{~mm} / \mathrm{s}$ the crack ratio decreases as the width increased, and no crack was observed when the width was wider than $100 \mathrm{~mm}$. A similar tendency was observed in cases of higher welding speeds, but the width which was necessary to give no crack increased. No crack was observed when the width was wider than $160 \mathrm{~mm}$. The restraint becomes larger as the width increases. Hence, increased restraint reduces the crack ratio due to less rotation, as discussed above.

Fig. 10 shows the relation between the crack ratio and the length $b$ of the reverse type test specimen shown in Fig. 11. This type of specimen was first proposed by Ando et al. ${ }^{3)}$.

Because the depth of slots is larger near the start of the welding in this specimen the restraint is smaller and the crack is easily developed here. The depth of slots becomes smaller as the distance from the edge of specimen increases, i.e.,

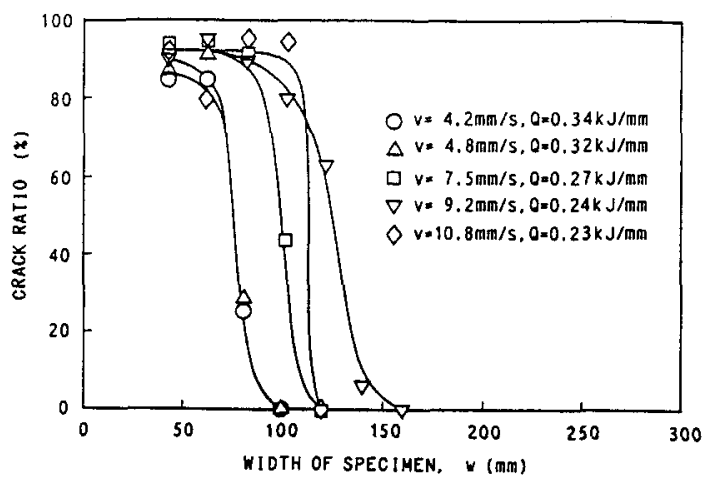

Fig. 9 Relation between crack ratio and width of the specimen.

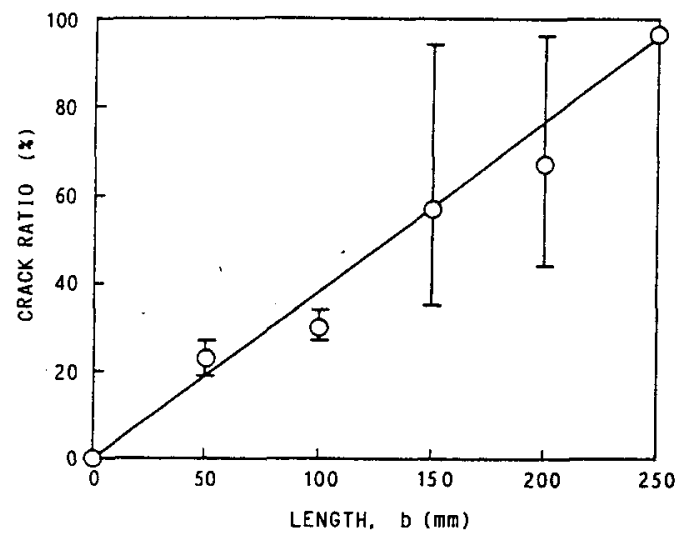

Fig. 10 Relation between crack ratio and length $b$ of the specimen shown in Fig. 11. the restraint becomes larger. The crack would stop when the restraint becomes large enough. The width of the specimen is $160 \mathrm{~mm}$, a value great enough to stop the crack, as is seen in Fig. 9. In this case the reflection of the heat can be ignored ${ }^{3)}$. The crack ratio increased linearly as the length $b$ increased, although large scatter of the data was observed in cases of the length equal to 150 and $200 \mathrm{~mm}$. It was decided to use the value of the length as $100 \mathrm{~mm}$, because the scatter of the data was very small in this case.

\subsection{Influence of welding conditions and solidification structures}

Fig. 12 shows the relation between the crack ratio and the heat input $q / t$. For this specimen type, unlike Fig. 5, the crack ratio increased as the heat input $q / t$ increased. This is due to the decreased restraint when the heat input $\mathrm{q} / \mathrm{t}$ increases. Fig. 13 shows the relation between the crack ratio and the heat input $Q / t$ for different welding speeds. At each welding speed the crack ratio increased when the heat input $Q / t$ increased due to less restraint. Since the crack ratio in-

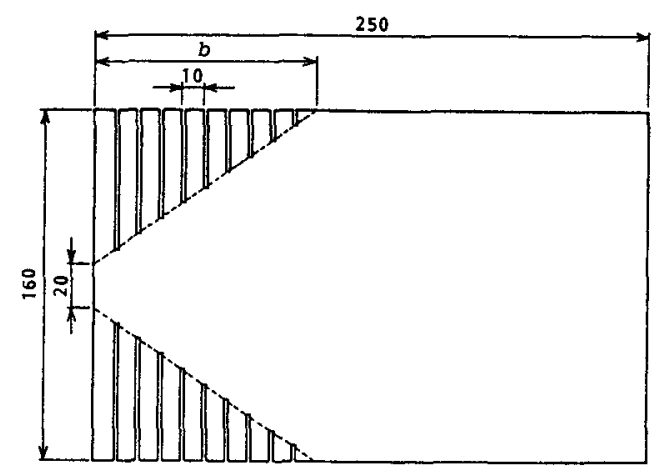

Fig. 11 Shape and dimensions of the specimen of the reverse Houldcroft type hot cracking test.

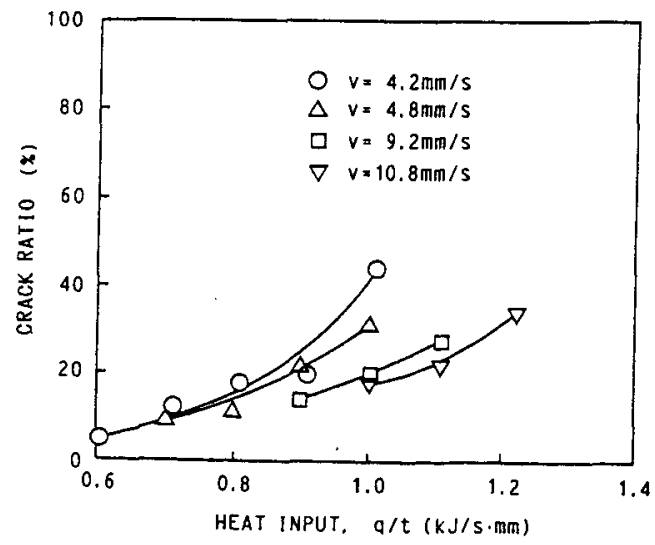

Fig. 12 Relation between crack ratio and heat input $\mathrm{q} / \mathrm{t}$ for the reverse type test. 


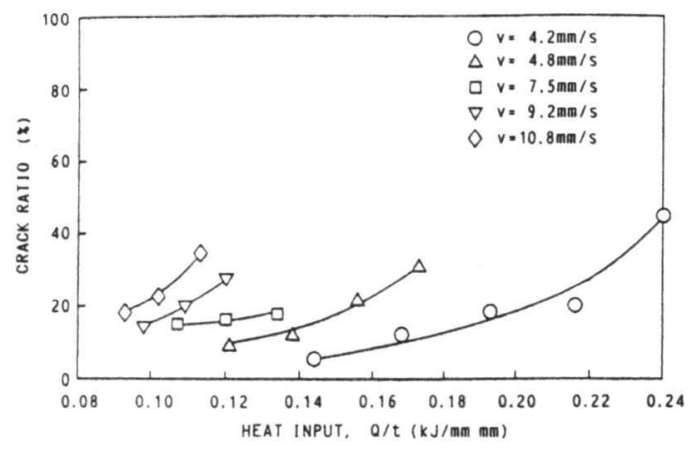

Fig. 13 Relation between crack ratio and heat input $\mathrm{Q} / \mathrm{t}$ for the reverse type test.

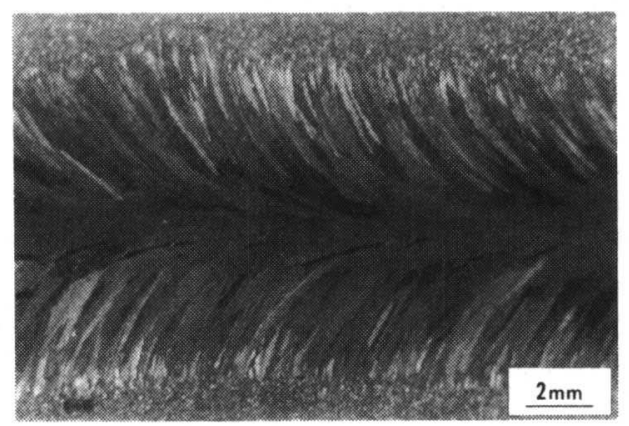

(a)

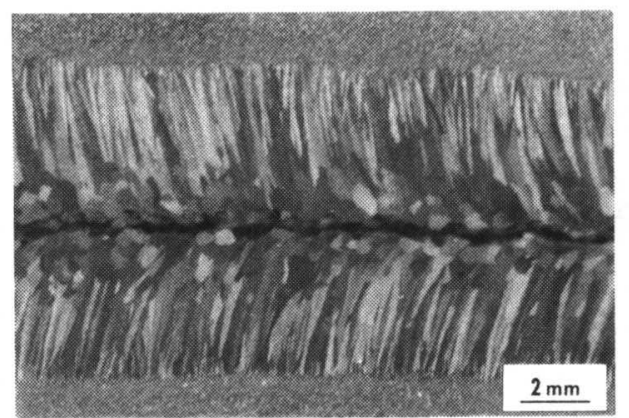

(b)

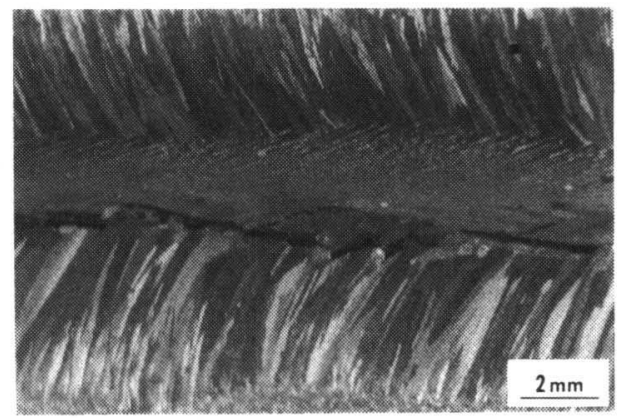

(c)

Fig. 14 Features of crack propagation. (a) Columnar crystal $(\mathrm{Q} / \mathrm{t}=0.17 \mathrm{~kJ} / \mathrm{mm}$. $\mathrm{mm}, \mathrm{v}=4.2 \mathrm{~mm} / \mathrm{s}$ ), (b) Equiaxed dendrite $(\mathrm{Q} / \mathrm{t}=0.17 \mathrm{~kJ} / \mathrm{mm} \cdot \mathrm{mm}, \quad \mathrm{v}=6.8$ $\mathrm{mm} / \mathrm{s})$, (c) Feathery crystal $(\mathrm{Q} / \mathrm{t}=0.12$ $\mathrm{kJ} / \mathrm{mm} \cdot \mathrm{mm}, \mathrm{v}=6.8 \mathrm{~mm} / \mathrm{s}$ ). creased when the reverse type specimens were used, as is usually experienced actually in welding, the reverse type test is recommended as a better test. At a given heat input $\mathrm{Q} / \mathrm{t}$, the crack ratio increased with faster welding speed. This is due to the increased gradient of the temperature distribution, as already discussed, plus the changes in solidification structures.

The solidification structures near the center of the weld metal change according to the welding conditions $^{9}$. At a low welding speed, columnar crystals are usually observed. When the welding was performed with a high weld heat input, equiaxed dendrites were sometimes developed. At a high welding speed, equiaxed dendrites were easily developed. In some cases feathery crystals were developed. Fig. 14(a), (b) and (c) show the features of crack propagation when the solidification structures were columnar crystals, equiaxed dendrites and feathery crystals, respectively. As already mentioned, the crack would propagate more easily in the case of equiaxed dendrites than in the case of columnar crystals. In the case of feathery crystals, the crack propagated mainly along the boundaries between the columnar crystals and the feathery crystals, without any cracking in the feathery crystals.

Fig. 15 shows the influence of solidification structures on the crack ratio. As is seen in Fig. 15 the columnar crystals were mainly observed at low heat inputs and the equiaxed dendrites were observed at high heat inputs. The feathery crystals were only observed in one welding condition. It can be seen from Fig. 15 that the crack ratio was smaller in the case of columnar crystals than in the case of the equiaxed dendrites.

\subsection{Study of rotation angle}

Fig. 16 shows the change of rotation angle

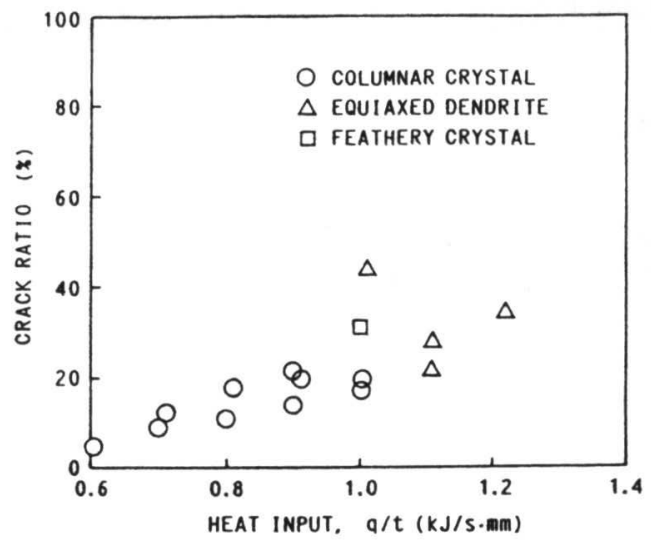

Fig. 15 Influence of solidification structures on crack ratio for the reverse type test. 


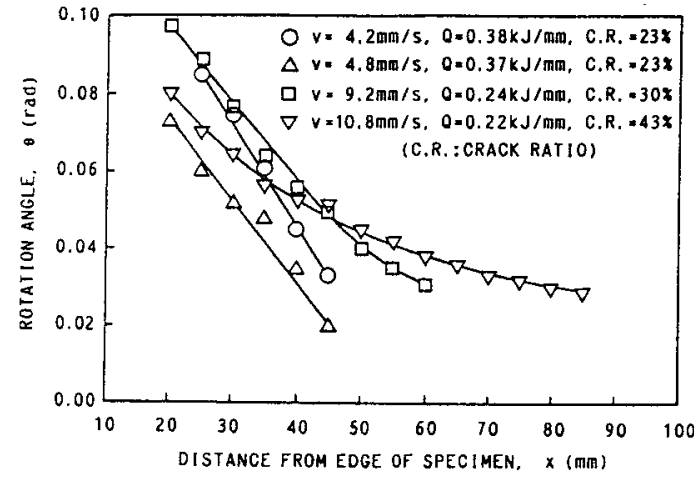

Fig. 16 Change of rotation angle in the process of crack propagation for the reverse type test.

during the process of crack propagation. The definition of the rotation angle is the same as shown in Fig. 2. In cases of $\mathrm{v}=4.2$ and $5.8 \mathrm{~mm} / \mathrm{s}$, the rotation angle had a larger value of about 0.08 rad near the start of the welding and decreased linearly as the crack propagated. The crack stopped when the rotation angle had a value from about 0.02 to $0.03 \mathrm{rad}$. At higher welding speeds, the length of the crack tended to be longer as discussed above and the slope of the rotation angle versus the distance decreased.

This study has shown that the rotational deformation is an important factor that affects the propagation and arrest of hot cracks in the Houldcroft type test.

\section{Conclusions}

The influences of the heat input and the solidification structure on the crack ratio have been studied for A5052 aluminum alloy using both the conventional and the reverse Houldcroft type hot cracking tests. The rotation angles were also measured using a video camera during welding. The main results obtained are as follows:

(1) In conventional Houldcroft type hot cracking test the crack ratio decreased linearly when the heat input $Q / t$ increased, where $Q=I \cdot E / v, I$ : welding current (A), E: arc voltage $(\mathrm{V}), \mathrm{v}$ : welding speed $(\mathrm{mm} / \mathrm{s})$ and $t$ : thickness of a specimen $(\mathrm{mm})$.

(2) The temperature distribution around the molten pool using an infrared camera tended to be more uniform for specimens with slots compared with specimens without slots.

(3) In the conventional type test the uniformity of the temperature distributions is proposed to strongly influence the arrest of the crack : steeper temperature gradients promote cracking.
(4) In the reverse type test, where the restraint is the main factor instead of the temperature distribution, the crack ratio increased when the heat input increased. This tendency is the same as is experenced actually in welding. Hence, the reverse type test is recommended as a better test. (5) Cracking propagated more easily in the case of equiaxed dendrites than in the case of columnar crystals.

(6) The rotation angle at the tip of the crack decreased gradually as the crack propagated in both tests. The crack stopped when the rotation angle reached the range from about 0.01 to 0.03 rad. The rotation angle was shown to clearly affect the propagation and arrest of the crack.

The authors would like to thank Professor $\mathrm{H}$. W. Kerr, University of Waterloo in Canada, for his very useful and kind discussions.

\section{- References}

1) P.T.Houldcroft: A Simple Cracking Test for Use with Argon Arc Welding, Brit. Weld. J., Vol. 10, No. 10, 471-475, (1955).

2) J.H. Rogerson, B. Cotterell, J.C. Borland: An Analysis and Evaluation of the Houldcroft Weld Cracking Test, Weld. J., Vol. 42, No.6, 264s-268s, (1963).

3) K. Ando, S. Nakata, K. Kishida, Y. Fujihira: Hot Cracking Phenomena of Thin Aluminum Alloy Plate (2nd Report), J. Japan Weld. S., Vol. 42, No.9, 879889, (1973) (in Japanese).

4) J.C. Borland: Weld. and M. Fab., Fundamentals of Solidification Cracking in Welds (Part 1), Vol. 47, No. 1/2, 19-29, (1979).

5) J.C. Borland: Weld. and M. Fab., Fundamentals of Solidification Cracking in Welds (Part 2), Vol. 47, No. 3, 99-106, (1979).

6) H. Nakagawa, M. Katoh, F. Matsuda, T. Senda : Trans. Japan Weld. S., Crystallographic Investigation for Origination of New Columnar Crystal in Aluminum Weld Metal Using Single Crystal Sheet, Vol. 2, No. 1, 1-9, (1971).

7) F. Matsuda, K. Nakata, K. Tsuakamoto, K. Arai: Effect of Additional Element on Solidification Crack Susceptibility of Al-Zn-Mg Alloy (Report II), Trans. Japan Weld. Research Inst., Vol. 12, No. 2, 93-102, (1983).

8) K. Ando, S. Nakata: A Calculation of Deformation of Rectangular Plate due to Heating, Preprint of National Meeting of Japan Weld. S., Vo. 10 (Spring), 305-306, (1972) (in Japanese)

9) H. Nakagawa, M. Katoh, F. Matsuda, T. Senda : Trans. Japan Weld. S., Formation Mechanism and Metallurgical Properties of the Feathery Crystal in Weld Metal of 5083 Aluminum Alloy Sheet, Vol.3, No. 2, 292-301, (1972). 